\title{
NOTCH4 signaling controls EFNB2-induced endothelial progenitor cell dysfunction in preeclampsia
}

\author{
Xiaoxia Liu, Qingqing Luo, Yanfang Zheng, Xiaoping Liu, Ying Hu, Weifang Liu, Minglian Luo, \\ Yin Zhao and Li Zou \\ Department of Obstetrics and Gynecology, Union Hospital, Huazhong University of Science and Technology, \\ Wuhan, China \\ Correspondence should be addressed to Li Zou; Email: 759898182@qq.com
}

\begin{abstract}
Preeclampsia is a serious complication of pregnancy and is closely related to endothelial dysfunction, which can be repaired by endothelial progenitor cells (EPCs). The DLL4/NOTCH-EFNB2 (ephrinB2) cascade may be involved in the pathogenesis of preeclampsia by inhibiting the biological activity of EPCs. In addition, both NOTCH1 and NOTCH4, which are specific receptors for DLL4/NOTCH, play critical roles in the various steps of angiogenesis. However, it has not been determined which receptor (NOTCH1, NOTCH4, or both) is specific for the DLL4/NOTCH-EFNB2 cascade. Accordingly, we performed a series of investigations to evaluate it. EFNB2 expression was examined when NOTCH4 or NOTCH1 was downregulated, with or without DLL4 treatment. Then, the effects of NOTCH4 on EPC function were detected. Additionally, we analyzed NOTCH4 and EFNB2 expression in the EPCs from preeclampsia and normal pregnancies. Results showed that NOTCH4 downregulation led to decreased expression of EFNB2, which maintained the same level in the presence of DLL4/NOTCH activation. By contrast, NOTCH1 silencing resulted in a moderate increase in EFNB2 expression, which further increased in the presence of DLL4/NOTCH activation. The downregulation of NOTCH4 resulted in an increase of EPC biological activity, which was similar to EFNB2 silencing. NOTCH4 expression, consistent with the EFNB2 level, increased notably in preeclampsia EPCs compared with the controls. These findings suggest that NOTCH4, not NOTCH1, is the specific receptor for the DLL4/NOTCH-EFNB2 cascade. Blockade of this cascade may enhance the angiogenic property of EPCs, and act as a potential target to promote angiogenesis in patients with preeclampsia.

Reproduction (2016) 152 47-55
\end{abstract}

\section{Introduction}

Preeclampsia is a hypertensive complication that affects $5-7 \%$ of all pregnancies. It is associated with significantly higher rates of maternal-fetal morbidity and mortality (ACOG 2013). The generally accepted pathogenesis of preeclampsia is a two-stage model (Agata Szpera-Gozdziewicz 2014). The first stage (before the 20th gestational week) is triggered by abnormal embryo implantation and poor placentation that leads to placental hypoxia. The second stage, which represents endothelial dysfunction, occurs after the 20th gestational week and is a result of the release of antiangiogenic factors due to hypoxia into the placental and maternal circulation. However, this dysfunction cannot be automatically repaired by terminally differentiated endothelial cells. Endothelial progenitor cells (EPCs) are considered to have the capacity for vascular endothelial repair (Agata Szpera-Gozdziewicz 2014).

EPCs are heterogeneous populations of endothelial cell precursors that are thought to play a role in endothelial homeostasis and vascular remodeling (Hur et al. 2004, Burger \& Touyz 2012). Reduction in number or malfunction of EPCs may be a risk factor for cardiovascular diseases (Hill et al. 2003, Di Mambro et al. 2010), and EPCs act as a treatment for animal ischemia models (Oh et al. 2007, Ye \& Poh 2015). Moreover, recent evidence supports the idea that EPCs may play a part in placental vasculature and the pathophysiology of preeclampsia (Robb et al. 2007, Sipos et al. 2010). EPCs increase gradually with gestational age in an uncomplicated pregnancy (Sugawara et al. 2005). The decrease and functional disorder of EPCs has been shown to reflect damaged endothelial repair ability in preeclampsia (Lin et al. 2009, Luppi et al. 2010). Therefore, defects in EPCs may be used as a diagnostic tool, while enhancement of EPCs may be used as a therapeutic tool with regard to preeclampsia.

Our recent studies have provided the novel insight that DLL4/NOTCH-EFNB2 (ephrinB2) cascade is part of the pathological mechanism of preeclampsia in the regulation of EPC activity (Liu et al. 2015). The evolutionarily conserved $\mathrm{NOTCH}$ signaling pathway plays a crucial role in intercellular communication and deciding the fate of cells during development 
(Artavanis-Tsakonas et al. 1999). The $\mathrm{NOTCH}$ family consists of four $\mathrm{NOTCH}$ receptors $(\mathrm{NOTCH} 1,2,3$, and 4) and five ligands (Jagged 1 and 2 and Deltalike 1, 3, and 4) in mammals (Weinmaster 1997). Notably, DLL4 is a pivotal vascular-specific element of the NOTCH pathway and contributes to embryonic vascular development and arteriogenesis (Duarte et al. 2004, Gale et al. 2004), by linking endothelial cell bioactivity to the tissue microenvironment via $\mathrm{NOTCH}$ ligand receptor signaling (Noguera-Troise \& Gale 2006, Ridgway et al. 2006). DLL4 was found to only interact with $\mathrm{NOTCH} 1$ and $\mathrm{NOTCH} 4$, endothelial cell-specific $\mathrm{NOTCH}$ receptors, which played a prominent role in angiogenesis and homeostasis during development (Shutter et al. 2000, Shawber et al. 2003). Strikingly, the activation of DLL4/NOTCH signaling led to repression of EPC proliferation, differentiation, and migration (Liu et al. 2015). NOTCH1 was also discovered to be involved in the inhibition of EPC activity (li et al. 2010); however, the influence of $\mathrm{NOTCH} 4$ on EPCs has not been thoroughly explored. EFNB2 is a membranebound ligand for EPH receptor tyrosine kinases, which are involved in numerous developmental processes (Christian Hafner 2004). EFNB2 is specifically expressed in endothelial cells, arterial angioblasts, and perivascular mesenchymal cells as a critical regulator of embryonic vessel development and vascular remodeling (Wang et al. 1998). EFNB2 has the ability to regulate the biological functions of differentiated endothelial cells (Steinle et al. 2003, Kuijper et al. 2007), including their growth, sprouting, migration, and proper assembly with other endothelial cells to form vascular structures (Salvucci \& Tosato 2012). As the downstream of DLL4/NOTCH signaling pathway, EFNB2 has been also discovered to play an inhibitory role on EPC function (Liu et al. 2015).

This study is based on the hypothesis that the decrease and dysfunction of EPC in preeclampsia could be rescued by appropriately modulating DLL4/NOTCH-EFNB2 cascade. Although the vital role of DLL4/NOTCHEFNB2 cascade in EPC bioactivity was determined, the specific receptor that interacts with DLL4 was not fully determined. DLL4 binding to different receptors exhibited different biological effects on vascular development. $\mathrm{NOTCH} 1$ or $\mathrm{NOTCH} 4$, or even both, are the suggested receptors for this cascade in EPCs. This hypothesis was tested by a number of investigations to evaluate the relationship between EFNB2 and DLL4/ $\mathrm{NOTCH} 1$ or DLL4/NOTCH4.

\section{Materials and methods}

\section{Population study}

The study groups consisted of 12 normotensive women and 12 preeclampsia women. All of the study participants were from the Department of Obstetrics and Gynecology, Union
Table 1 Clinical characteristics of study population.

\begin{tabular}{lccc}
\hline Parameters & $\begin{array}{c}\text { Normal } \\
(n=12)\end{array}$ & $\begin{array}{c}\text { Preeclampsia } \\
(n=12)\end{array}$ & $\boldsymbol{P}$-value \\
\hline Maternal age (years) & $29.65 \pm 1.04$ & $31.00 \pm 1.55$ & $>0.05$ \\
BMI in pregnancy & $25.66 \pm 0.57$ & $26.07 \pm 0.87$ & $>0.05$ \\
Gestational weeks at & $38.34 \pm 0.23$ & $36.54 \pm 0.56$ & $<0.05$ \\
$\quad$ delivery & & & \\
SBP at delivery & $113.42 \pm 1.20$ & $158.74 \pm 6.71$ & $<0.05$ \\
DBP at delivery & $75.42 \pm 1.34$ & $102.16 \pm 2.90$ & $<0.05$ \\
Proteinuria & $0 \%(0 / 12)$ & $100 \%(12 / 12)$ & $<0.05$ \\
S/D ratio of umbilical & $2.21 \pm 0.09$ & $2.30 \pm 0.04$ & $>0.05$ \\
$\quad$ artery & $3410 \pm 82.13$ & $2997 \pm 83.61$ & $<0.05$ \\
Birth weight (g) & $9.05 \pm 0.18$ & $8.02 \pm 0.33$ & $<0.05$ \\
Apgar score & & &
\end{tabular}

Data is presented as mean \pm S.D. or percentage (number/total). $\mathrm{BMI}$, body mass index in pregnancy $\left(\mathrm{kg} / \mathrm{m}^{2}\right)$; $\mathrm{SBP}$, systolic blood pressure; DBP, diastolic blood pressure; S/D ratio, systole/diastole (S/D) ratio; Proteinuria (quantity of $24 \mathrm{~h}$ urine protein excretion), higher or equal to $300 \mathrm{mg} / 24 \mathrm{~h}$ is proteinuria positive; lower than $300 \mathrm{mg} / 24 \mathrm{~h}$ is proteinuria negative.

Hospital, Huazhong University of Science and Technology (HUST) and signed the informed consent. Ethical approval was obtained from the hospital's Ethics Committee. All subjects were beyond the 32th gestational week. Preeclampsia was clinically described as hypertension (blood pressure greater or equal to $140 / 90 \mathrm{mmHg}$ ) and proteinuria (greater or equal to $300 \mathrm{mg} / 24 \mathrm{~h}$ ) that occurred after the 20th gestational week (ACOG 2013). Members of control group were healthy pregnant women without pregnancy complications or any chronic problems. Exclusion criteria included multiple pregnancies, rupture of membranes, fetal structural, or genetic anomalies (e.g., hepatic disease, diabetes, cardiovascular diseases, blood diseases, or other organic and metabolic disorders, and infectious disease). Clinical characteristics of the two groups are given in Table 1. After cutting the umbilical cord, cord blood (40-60 mL) was immediately collected and processed for cell culture.

\section{Isolation and culture of EPCs}

The method adopted for EPC isolation from cord blood was as described previously (Yan et al. 2013). It has been demonstrated that EPCs can be induced and differentiated from mononuclear cells (MNCs) in peripheral blood (Hur et al. 2007). MNCs were isolated from $50 \mathrm{~mL}$ of cord blood by the density gradient centrifugation method $\left(400 \mathrm{~g}, 30 \mathrm{~min}, 20^{\circ} \mathrm{C}\right)$. The collected MNCs were washed twice using a phosphatebuffer solution (PBS) and then re-suspended $\left(1 \times 10^{6}\right.$ cells $\left./ \mathrm{mL}\right)$ in endothelial basal medium-2 (EBM-2; Lonza, Allendale, NJ, USA) containing $10 \%$ fetal bovine serum (FBS) and cultured in pre-coated six-well culture dishes (Corning) with fibronectin (Sigma-Aldrich). The cells were incubated in a $5 \% \mathrm{CO}_{2}$ humidified atmosphere at $37^{\circ} \mathrm{C}$ and the medium was replaced every 3 days. Attached cells formed small EPC clusters after 3 days. Cells from the central core of these clusters gradually became elongated and acquired spindleshaped. Colony-forming units (CFU) (Hur et al. 2007) began to materialize on day 7 , when all experiments were carried out. The identification of EPCs on day 7 has been performed in our previous study (Yan et al. 2013). 


\section{Quantitative RT-PCR}

Total RNA was extracted from cultured cells using RNAiso Plus (Takara Bio). This was followed by cDNA synthesis using PrimeScript $^{\text {TM }}$ 1st RT Master Mix (Takara, Japan). The primer sequence was as follows: GAPDH (an internal control), forward primer: 5'-ACCACAGTCCATGCCATCAC-3', reverse primer: 5'-TCCACCACCCTGTTGCTGTA-3'. NOTCH4, forward primer: 5'-CACTAGGCGAGGACAGCATTG-3', reverseprimer:5'-ATTCC TGGGGAGGAGTTAGCA-3'. NOTCH1, forwardprimer:5'-GAGA AGGGAAGTTGAACGAGCAT-3', reverse primer: 5' - TGCCTCCG TTTGCCTCTGG-3'. EFNB2, forward primer: $5^{\prime}$-GGTGGTCCTC TTGCTGAAGT-3' ${ }^{\prime}$, reverse primer: $5^{\prime}$-CGCTGACCTTCTCGTAG TGA-3'. HES1, forward primer: 5' -CTACCCCAGCCAGTGTCAA CA-3', reverse primer: 5'-AACGCAGTACCGGCGAGTG-3'. HEY1, forward primer: 5'-CGGCAGGAGGGAAAGGCTA-3', reverse primer: 5'-CGGGTGATGTCCAAAGGCAG-3'. Quantitative RT-PCR (qRT-PCR) was performed on the StepOne ${ }^{T M}$ RealTime PCR System with SYBR Premix Ex Taq ${ }^{\text {TM }}$ (TaKaRa, Japan) according to the manufacturer's protocol. The qRT-PCR reaction consisted of a $95^{\circ} \mathrm{C}$ denaturation step for $30 \mathrm{~s}, 40$ cycles $\left(95^{\circ} \mathrm{C}\right.$ for $5 \mathrm{~s}, 65.5^{\circ} \mathrm{C}$ for $30 \mathrm{~s}, 60^{\circ} \mathrm{C}$ for $45 \mathrm{~s}$ ) and extension at $72^{\circ} \mathrm{C}$ for $60 \mathrm{~s}$. The expression of target genes was calculated using the $2^{-\triangle \Delta C T}$ method.

\section{Western blot analysis}

EPCs with different treatment or from controls and preeclampsia patients were lysed in a RIPA lysis buffer. The supernatant protein concentration was determined using a BCA protein assay kit (Beyotime, China), after which $50 \mu \mathrm{g}$ proteins were separated on $10 \%$ sodium dodecyl sulfate-polyacrylamide gel electrophoresis (SDS-PAGE) and transferred onto polyvinylidene fluoride (PVDF) membranes. The membranes were then incubated with primary antibodies against NOTCH4 (1.0 $\mu \mathrm{g} / \mathrm{mL}$; Millipore), NOTCH1 $(1.0 \mu \mathrm{g} / \mathrm{mL}$; Abcam), EFNB2 $(0.5 \mu \mathrm{g} / \mathrm{mL}$; Abcam), and GAPDH $(0.5 \mu \mathrm{g} / \mathrm{mL}$; Affinity, Cincinnati, $\mathrm{OH}, \mathrm{USA})$ at $4{ }^{\circ} \mathrm{C}$ overnight. Incubated membranes were developed by appropriate anti-rabbit secondary antibodies $(0.5 \mu \mathrm{g} / \mathrm{mL}$; ProteinTech, Chicago, IL, USA) for $1 \mathrm{~h}$ at room temperature and signals were visualized using enhanced chemiluminescence (ECL; Beyotime, China).

\section{Transfection}

We established the silence model in normal EPCs to further study the relationship between EFNB2, NOTCH4 and NOTCH1 in EPCs. Cultured EPCs $\left(4 \times 10^{5}\right.$ cells/well $)$ were divided into five groups: (1) nontransfected cells (control group); (2) transfected cells with DNA plasmid of nonspecific sequence as a negative control (shNC group); (3) transfected cells with DNA plasmid against $\mathrm{NOTCH} 4$ expression (shNOTCH4 group) (Genechem, Shanghai, China); (4) transfected cells with DNA plasmid against NOTCH1 expression (shNOTCH1 group) (Genechem, Shanghai, China); and (5) negative control for shNOTCH1 group (shNC1 group). Transfection was completed using Neofect (Neofect Biotechnologies, Beijing, China) according to th manufacturer's protocol. The inhibition efficiency of target genes was verified using qRT-PCR and western blot assay.

\section{Reagents}

The NOTCH signaling pathway was activated in EPCs using s-DLL4 recombinant protein $(0.2 \mu \mathrm{g} / \mathrm{mL}$; PeproTech, Rocky Hill, NJ, USA). Normal and transfected EPCs were incubated with s-DLL4 for $24 \mathrm{~h}$ (Liu et al. 2015). According to the manufacturer's instruction, recombinant human s-DLL4 comprises the extracellular signaling domain of DLL, a member of a structurally-related family of single-pass type I transmembrane proteins that serve as ligands for $\mathrm{NOTCH}$ receptors. s-DLL4 functions to specifically activate the $\mathrm{NOTCH} 1$ and $\mathrm{NOTCH} 4$ receptors.

\section{Cell proliferation assay}

The influence of $\mathrm{NOTCH} 4$ on cell proliferation was evaluated using the Cell Counting Kit (CCK-8) assay. EPCs $\left(2.5 \times 10^{4}\right.$ cells/well $)$ with different treatment were cultured on 96 -well plates in five replicates. After $24 \mathrm{~h}, 10 \mu \mathrm{L}$ of a CCK-8 solution (Dojindo, Kumamoto, Japan) was added to each well and incubated for $4 \mathrm{~h}$ at $37^{\circ} \mathrm{C}$. The absorbance of each well was measured at $450 \mathrm{~nm}$ using a microplate reader (Model 550; Bio-Rad). All experiments were carried out three times.

\section{Cell differentiation assay}

Cell differentiation assay was carried out as described previously (Yan et al. 2013). EPCs $\left(2.5 \times 10^{4}\right.$ cells/well) with different treatment were re-suspended and re-plated on 96-well fibronectin-coated culture dishes. After $24 \mathrm{~h}$ incubation at $37^{\circ} \mathrm{C}$ in a $5 \% \mathrm{CO}_{2}$ incubator, the number of elongated and spindleshaped cells, representing differentiated EPCs according to the report by Asahara (Asahara et al. 1997), was counted in three random fields at 200× magnification using a phase-contrast microscope. We also normalized differentiated cells to the total number of cells.

\section{Migration assay}

The migration ability of EPCs was detected using Transwells $(8.0 \mu \mathrm{m}$ pore size; Corning). Transfected cells were briefly re-suspended in $200 \mu \mathrm{l}$ of EBM-2 and then added to the upper chamber $\left(5 \times 10^{4}\right.$ cells/chamber $)$. At the same time, the lower chamber was filled with $550 \mu \mathrm{L}$ of a medium containing $10 \%$ FBS and $50 \mathrm{ng} / \mathrm{mL}$ of recombinant human VEGF ${ }_{165}$ (PeproTech, Rocky Hill, NJ, USA) as a chemoattractant. After $24 \mathrm{~h}$ incubation at $37^{\circ} \mathrm{C}$, nonmigrated cells were removed using a cotton-tipped swab while migrated cells were fixed with $4 \%$ formaldehydum polymerisatum and stained with crystal violet. The migrated cells were imaged and counted (three randomly selected fields per Transwell at 200× magnification) using an inverted microscope.

\section{Adhesive assay}

EPC adhesion was carried out as described previously (Liang et al. 2009). EPCs $\left(2.5 \times 10^{4}\right.$ cells/well $)$ from different groups were re-suspended in $0.25 \%$ trypsin and incubated in fibronectin-coated culture plates containing EBM-2 with $10 \%$ FBS. After further incubation for $0.5 \mathrm{~h}$, nonadherent cells were 
washed off using PBS. Adherent cells were counted in three random fields (at 200× magnification).

\section{In vitro HUVEC tube formation assay}

On day 7, EPCs failed to form tube-like structures but promoted human umbilical vein endothelial cell (HUVEC) to form tube-like structures by secreting angiogenic cytokines (Hur et al. 2004). Therefore, we conducted HUVEC tube formation assay in vitro. First, the medium that had cultured transfected cells was collected. HUVECs $\left(3.5 \times 10^{4}\right.$ cells/well $)$ were then harvested, re-suspended in $100 \mu \mathrm{L}$ of a conditioned medium, and re-seeded on 96-well plates coated with growth factor reduced Matrigel (BD, Franklin Lakes, NJ, USA). After $8 \mathrm{~h}$ incubation at $37^{\circ} \mathrm{C}$, tube-like structures were formed and observed by microscopy (at 100x magnification). To quantitate the progression of angiogenesis, the mean number of branching points with at least three tubules was counted in five randomly selected fields per well (Huang \& Zheng 2006).

\section{Statistical analysis}

We used GraphPad Prism 5 for data analysis. The analysis of variance (ANOVA) followed by post hoc test was applied in the comparison among groups, and the results were expressed as means \pm S.D. A $P$-value of less than 0.05 was considered to be statistically significant.

\section{Results}

\section{Clinical characteristics of study population}

The clinical characteristics of study population were summarized in Table 1. There was no statistical difference in maternal age, BMI, and S/D ratio between preeclampsia patients and controls. Preeclampsia patients presented earlier pregnancy termination than controls $(P<0.05)$. Both neonatal weight and Apgar scores were lower in preeclampsia group $(P<0.05)$.

\section{NOTCH4 and NOTCH1 silence in EPCs}

Transfection efficiency was verified by qRT-PCR and western blot assay. The mRNA level of NOTCH4 decreased substantially in the shNOTCH4 group compared with the shNC group (Fig. 1A). Similarly, the expression of $\mathrm{NOTCH} 4$ protein was significantly lower in the shNOTCH4 group (Fig. $1 \mathrm{~B}$ and $\mathrm{E}$ ). There was a decrease in NOTCH1 mRNA (Fig. 1C) and protein level (Fig. 1D and F) in the shNOTCH1 group compared with the controls.

\section{Activation of NOTCH signaling by s-DLL4}

To testify that s-DLL4 recombinant protein can activate $\mathrm{NOTCH}$ signaling pathway in EPCs, the mRNA levels of target genes, such as HES1 and HEY1 (Williams et al. 2006), were monitored by qRT-PCR. Results showed that
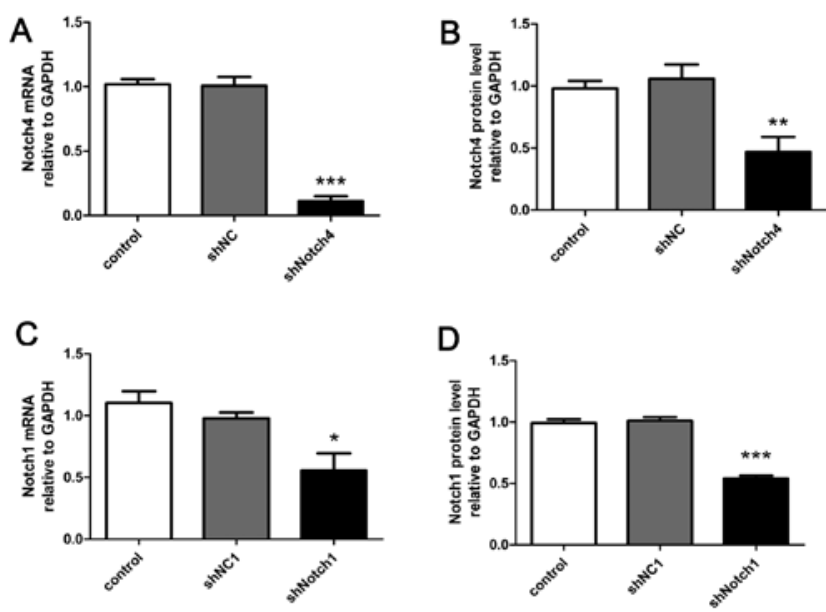

E

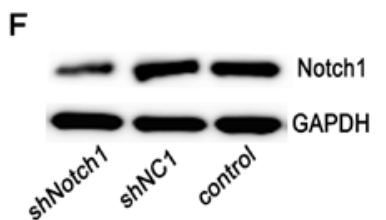

Figure 1 Transfection influenced the expression of $\mathrm{NOTCH} 4$ and NOTCH1 in EPCs. (A) The mRNA expression of NOTCH4 in EPCs from shNOTCH4 groups decreased notably compared with shNC groups $(0.11 \pm 0.02$ vs $1.01 \pm 0.03, P<0.001)$. There was no significant difference of NOTCH4 mRNA between control and negative control $(P=0.751, P>0.05)$. (B) There was a distinct obvious drop of $\mathrm{NOTCH} 4$ protein level in shNOTCH4 groups compared with controls $(0.47 \pm 0.07$ vs $1.06 \pm 0.07, P<0.01)$. NOTCH4 protein level did not have a significant change between control and negative control $(P>0.05)$. (C and D) There was a drop in NOTCH1 mRNA $(0.56 \pm 0.14$ vs $0.98 \pm 0.05, P<0.05)$ and protein $(0.54 \pm 0.01$ vs $1.01 \pm 0.02, P<0.001)$ level in shNOTCH1 group compared with controls. NOTCH1 mRNA $(P>0.05)$ and protein $(P>0.05)$ expression did not have a significant change between control and negative control. ( $\mathrm{E}$ and $\mathrm{F}$ ) $\mathrm{NOTCH} 4$ and $\mathrm{NOTCH} 1$ protein expression in different groups was shown by western blotting. ${ }^{*} P<0.05$; ${ }^{*} P<0.01 ; * * * P<0.001$; shNOTCH4 group (NOTCH4 silence); shNOTCH1 group (Notch1 silence); shNC group (negative control to shNOTCH4 group); shNC1 group (negative control to shNOTCH1 group).

the expression of HES1 and HEY1 was higher in DLL4 group than control (Fig. 2A and B).

\section{Effects of NOTCH4 silence on EFNB2 expression}

The downregulation of $\mathrm{NOTCH} 4$ in EPCs significantly inhibited EFNB2 mRNA (Fig. 2C) and protein expression (Fig. 2D and G) compared with the shNC group. Moreover, EFNB2 mRNA (Fig. 2C) and protein expression (Fig. 2D and G) was also downregulated in NOTCH4silcenced EPCs cultured with s-DLL4 compared with the shNC group. There was no significant difference in EFNB2 expression between the shNOTCH4 group and shNOTCH4+DLL4 group (Fig. 2C, D and G). These indicated that EFNB2 expression may be dominated by $\mathrm{NOTCH} 4$ signaling. 

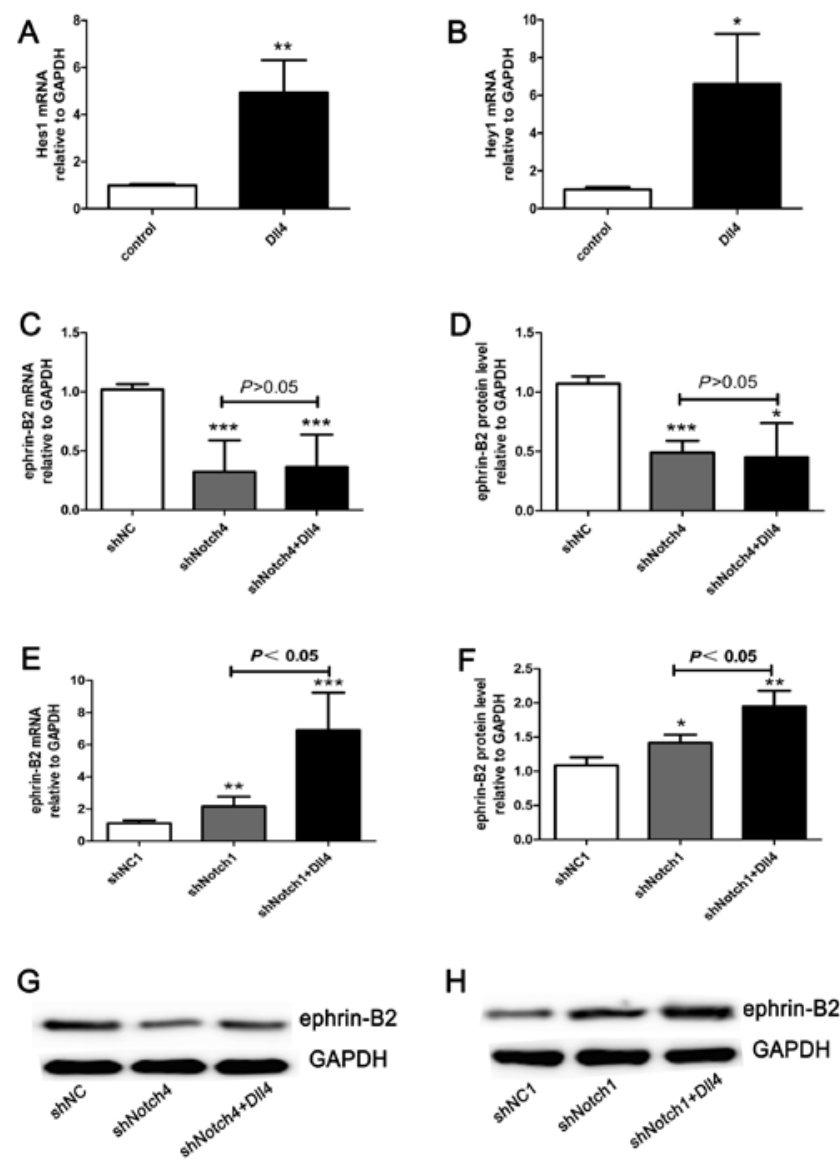

Figure 2 Transfection and reagent influenced EFNB2 expression in EPCs. (A and B) The mRNA levels of HES1 ( $4.94 \pm 0.80$ vs $0.99 \pm 0.03, P<0.01)$ and HEY $1(6.60 \pm 1.54$ vs $1.01 \pm 0.07, P<0.05)$ in EPCs cultured with sDLL4 were higher than in controls. (C and D) The mRNA expression $(0.32 \pm 0.08$ vs $1.02 \pm 0.02, P<0.001)$ and protein level $(0.49 \pm 0.06$ vs $1.07 \pm 0.04, P<0.001)$ of EFNB2 in EPCs from shNOTCH4 group significantly dropped compared with shNC group. EFNB2 mRNA $(0.37 \pm 0.12$ vs $1.02 \pm 0.20, P<0.001)$ and protein expression $(0.45 \pm 0.17$ vs $1.07 \pm 0.04, P<0.05)$ was also obviously downregulated in transfected EPCs cultured with DLL4, compared with shNC groups. There was no significant difference in EFNB2 expression between shNOTCH4 group and shNOTCH4 + DLL4 groups $(P>0.05)$. (E and F) EEFNB2 mRNA $(2.17 \pm 0.28$ vs $1.12 \pm 0.08, P<0.01)$ and protein expression $(1.42 \pm 0.07$ vs $1.09 \pm 0.07, P<0.05)$ slightly increased in shNOTCH1 group, compared with the shNC1 group. EEFNB2 mRNA $(6.90 \pm 1.05$ vs $1.12 \pm 0.08, P<0.001)$ and protein expression $(1.95 \pm 0.13$ vs $1.09 \pm 0.07, P<0.01$ ) were significantly up-regulated in shNOTCH1 + DLL4 group compared to control. Moreover, there was more EFNB2 mRNA $(6.90 \pm 1.05$ vs $2.17 \pm 0.28, P<0.01)$ and protein $(1.95 \pm 0.13$ vs $1.42 \pm 0.07, P<0.05)$ expression of shNOTCH $1+$ DLL4 group than shNOTCH1 group. (G and $\mathrm{H}$ ) EFNB2 protein expression in different groups was shown by western blotting. ${ }^{*} P<0.05$;

${ }^{* *} P<0.01$; ${ }^{* *} P<0.001$; shNOTCH4 group (NOTCH4 silence); shNC group (negative control to shNOTCH4 group); shNOTCH1 group (NOTCH1 silence); shNC1 group (negative control to shNOTCH1 group); shNOTCH1 + DLLL4 group (NOTCH1-silence EPCs cultured with DLL4); shNOTCH4+DLL4 group (NOTCH4-silence EPCs cultured with DLL4).

\section{Effects of NOTCH1 silence on EFNB2 expression}

EFNB2 mRNA (Fig. 2E) and protein level (Fig. 2F and H) increased slightly in shNOTCH1 group, compared with the shNC1 group. EFNB2 mRNA (Fig. 2E) and protein expression levels (Fig. 2F and $\mathrm{H}$ ) were significantly upregulated in $\mathrm{NOTCH} 1$-silence EPCs cultured with s-DLL4. Moreover, there was more EFNB2 mRNA (Fig. 2E) and protein (Fig. 2F and $\mathrm{H}$ ) expression in the shNOTCH1+DLL4 group compared with the shNOTCH1 group. These indicated that DLL4/NOTCH1 signaling pathway was not the direct upstream regulator of EFNB2.

\section{Effects of NOTCH4 on proliferation and differentiation of EPCs}

Compared with controls, there was a significant increase in cell proliferation following the downregulation of NOTCH4 (Fig. 3A). The number of differentiated cells in the shNOTCH4 group increased noticeably compared with the control group (Fig. 3B and D). Furthermore, the percentage of differentiated cells among all cells was higher in the shNOTCH4 group compared with the shNC group (Fig. 3C and D).

\section{Effects of NOTCH4 on migration and adhesion of EPCs}

Transwell assay showed that more EPCs from the shNOTCH4 group crossed the membrane compared with the shNC group (Fig. 4A and B), and adhesive assay showed that there were more adherent EPCs in the shNOTCH4 group compared with the shNC group (Fig. 4C and D).

\section{NOTCH4 mediated HUVEC tube formation in vitro}

We cultured HUVECs with different conditioned media in order to investigate the effect of $\mathrm{NOTCH} 4$ on angiogenesis. HUVECs cultured with supernatant collected from EPCs in the shNOTCH4 group formed more tube-like structures than those cells cultured with supernatant from the shNC group (Fig. 4E and F). All of the above suggested that NOTCH4 downregulated EPC function.

\section{NOTCH4 and EFNB2 expression in preeclampsia EPCs and control EPCs}

$\mathrm{NOTCH} 4$ and EFNB2 expression was tested in EPCs using qRT-PCR and western blot assay. Compared with the controls, the mRNA level of NOTCH4 increased notably in preeclampsia EPCs (Fig. 5A). Western blot assay showed the same trend for protein level with mRNA expression (Fig. 5B and G). The mRNA and protein levels of EFNB2 in preeclampsia EPCs were higher compared with healthy controls (Fig. 5C, D and H). As shown in 

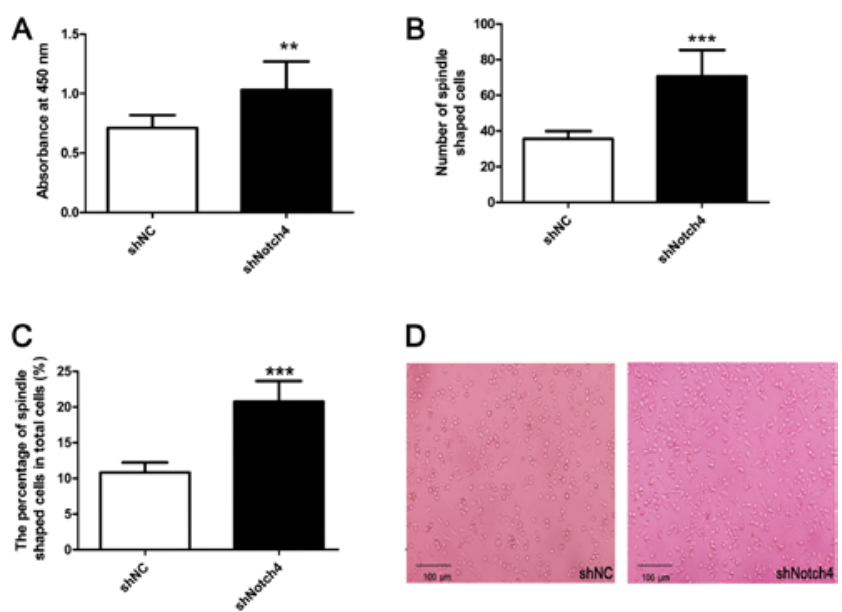

Figure $3 \mathrm{NOTCH} 4$ negatively regulated EPC proliferation and differentiation. (A) Downregulation of $\mathrm{NOTCH} 4$ promoted EPC proliferation in shNOTCH4 group (1.03 \pm 0.07 vs $0.71 \pm 0.04$, $P<0.01$ ). (B and C) Histogram showed the average number of spindle-shaped cells increased in shNOTCH4 group $(63.22 \pm 2.30$ vs $36.33 \pm 1.05, P<0.001)$. The percentage of differentiated cells increased in shNOTCH4 group $(20.78 \pm 1.16$ vs $10.83 \pm 0.58$, $P<0.001)$ compared with shNC group. (D) The number of spindleshaped cells under a phase-contrast microscope represented EPCs differentiation ability. ${ }^{* * P}<0.01,{ }^{* *} P<0.001$; shNOTCH4 group (NOTCH4 silence); shNC group (negative control to shNOTCH4 group).

Fig. 3E and F, NOTCH4 mRNA levels were moderately positively correlated with EFNB2 mRNA $(R=0.79$, $P<0.05)$, as well as protein level $(R=0.64, P<0.05)$. These results once again indicated that $\mathrm{NOTCH} 4$ may act as an upstream of EFNB2.

\section{Discussion}

EPCs contribute to vascular remodeling and endothelial homeostasis, by their proliferation, migration to the place where vessel formatting, differentiation into mature endothelial cells and secretion of paracrine factors (Sipos et al. 2010, Burger \& Touyz 2012). EPCs dysfunction may be involved in the pathogenesis of preeclampsia (Szpera-Gozdziewicz \& Breborowicz 2014). If the molecular mechanisms that regulate the functions of EPCs can be elucidated, it may be able to discover feasible treatment to promote angiogenesis in patients with preeclampsia. In our recent studies, a number of investigations related to the DLL4/NOTCHEFNB2 signaling pathway were carried out in order to evaluate its role on EPCs in the pathophysiology of preeclampsia (Liu et al. 2015). Results showed that both DLL4/NOTCH signaling pathway and EFNB2 inhibited the biological functions of EPCs. Additionally, the activation of the DLL4/NOTCH signaling pathway resulted in the upregulation of EFNB2 expression. However, it remained unclear if $\mathrm{NOTCH} 4$ or NOTCH1 was the specific receptor for DLL4/NOTCH-EFNB2
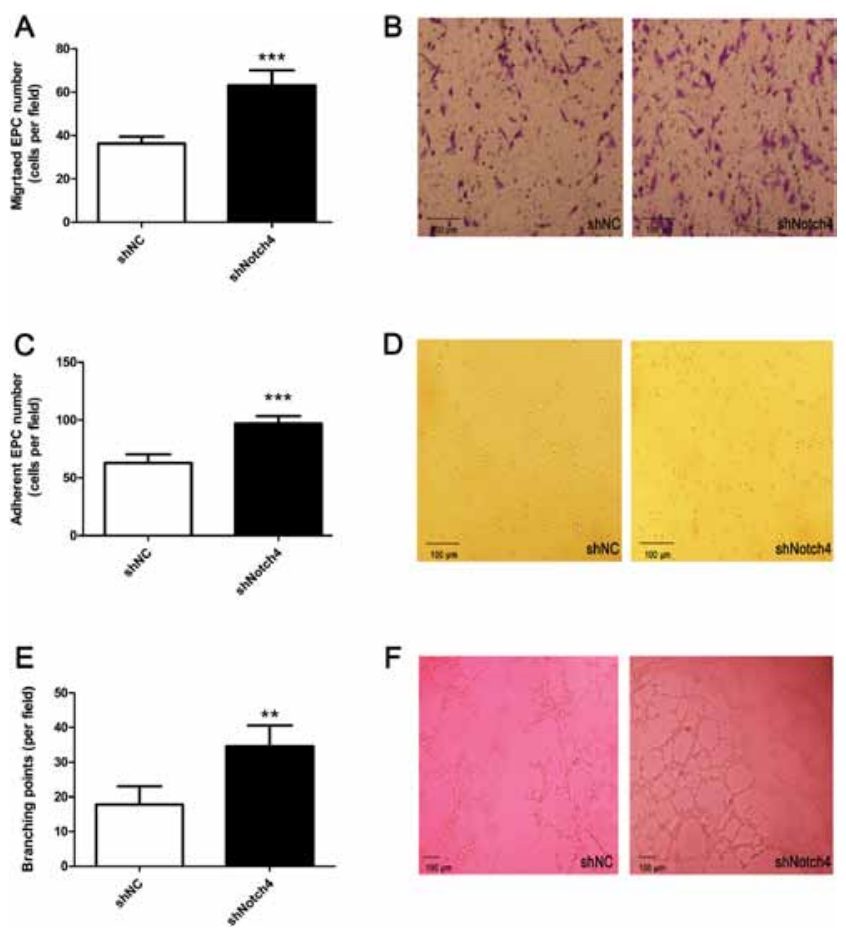

Figure 4 The influence of NOTCH4 on EPC migration, adhesion, and HUVEC-tube formation in vitro. (A) The migration ability of EPCs was increased after inhibition of $\mathrm{NOTCH} 4$ compared to control $(63.22 \pm 2.30$ vs $36.33 \pm 1.05, P<0.001)$. (C) NOTCH4 promoted EPCs adhesion compared with shNC group $(96.89 \pm 2.19$ vs $62.78 \pm 2.56, P<0.001$ ). (E) HUVECs cultured in the supernatant collected from shNOTCH4 group formed more branching points than $\operatorname{shNC}$ group $(34.60 \pm 2.68$ vs $17.80 \pm 2.35, P<0.01)$. (B, D and $F)$ Representative images displayed EPC migration, adhesion, and HUVEC tube formation in vitro. ${ }^{*} P<0.01$; ${ }^{* *} P<0.001$; shNOTCH4 group (Notch4 silence); shNC group (negative control to shNOTCH4 group).

cascade in preeclampsia. To explore this further, we have carried out a series of investigations from molecular and functional perspectives.

The first part of our research showed that the downregulation of $\mathrm{NOTCH} 4$ resulted in a decrease in the EFNB2 level of EPCs, which indicated that EFNB2 expression was dominated by $\mathrm{NOTCH} 4$ signaling. To further confirm DLL4/NOTCH4-EFNB2 cascade, we used s-DLL4 to activate the DLL4/NOTCH signaling pathway in NOTCH4-downregulated EPCs and EFNB2 expression remained low. This phenomenon further clarified that DLL4/NOTCH activation did not influence EFNB2 expression when $\mathrm{NOTCH} 4$ was silenced. At this point, $\mathrm{NOTCH} 4$ is likely the upstream regulator of EFNB2. However, EFNB2 increased slightly in NOTCH1-downregulated EPCs. DLL4 contacts with only two receptors, either $\mathrm{NOTCH} 1$ or $\mathrm{NOTCH} 4$, in a relatively balanced state (Shutter et al. 2000, Shawber et al. 2003). DLL4/NOTCH4, which enhanced EFNB2 expression, was the dominant pathway in the case of the downregulation of NOTCH1. EFNB2 expression increased when NOTCH1downregulated EPCs were 

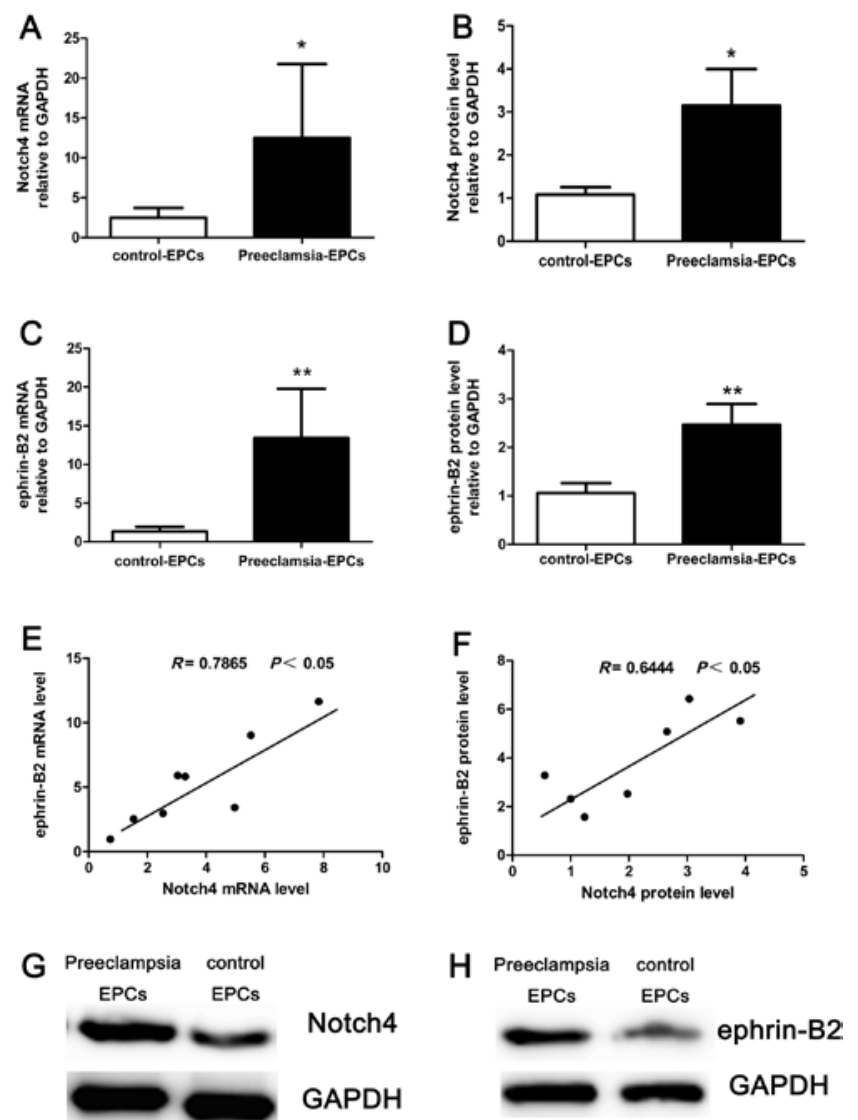

Figure $5 \mathrm{NOTCH} 4$ and EFNB2 expression in preeclampsia EPCs and control EPCs. (A and B) The mRNA $(12.49 \pm 4.63$ vs $2.49 \pm 0.46$, $P<0.05)$ and protein $(3.15 \pm 0.49$ vs $1.08 \pm 0.10, P<0.05)$ levels of $\mathrm{NOTCH} 4$ were higher in preeclampsia EPCs than in controls. (C and D) The mRNA $(13.43 \pm 3.18$ vs $1.33 \pm 0.30, P<0.01)$ and protein $(2.47 \pm 0.24$ vs $1.06 \pm 0.12, P<0.01)$ levels of EFNB2 were higher in preeclampsia EPCs than in healthy controls. (E and F) NOTCH4 mRNA levels were moderately positively correlated with EFNB2 mRNA $(R=0.79, P<0.05)$, as well as protein level $(R=0.64, P<0.05)$. $(\mathrm{G}$ and $\mathrm{H})$ Representative western blotting showed $\mathrm{NOTCH} 4$ and EFNB2 protein expression in different groups. ${ }^{*} P<0.05$; ${ }^{* *} P<0.01$.

treated with s-DLL4, which also may be caused by more DLL4/NOTCH4 activation. These results confirmed that EFNB2 is not a direct target of DLL4/NOTCH1 signaling in EPCs. From genetic and molecular perspectives, these results implied that EFNB2 occurred downstream of $\mathrm{NOTCH} 4$ signaling in EPCs. The second part of our research was to test whether $\mathrm{NOTCH} 4$ inhibit EPC function, similar to EFNB2. To further explore it, we downregulated $\mathrm{NOTCH} 4$ and then detected changes in EPC activity. The results showed that $\mathrm{NOTCH} 4$ silence in EPCs stimulated migration, proliferation, and differentiation. In turn, this demonstrated that $\mathrm{NOTCH} 4$ acts as an inhibitor of the functions of EPCs, similar to EFNB2 (Liu et al. 2015). Additionally, we found that the supernatant, which was collected from NOTCH4slienced EPCs, promoted the formation of HUVEC tube-like structures, which was also consistent with silenced EFNB2. Functional analyses confirmed that
EFNB2 may be a direct target of $\mathrm{NOTCH} 4$ signaling. Finally, we conducted additional investigations to verify the relationship between preeclampsia and $\mathrm{NOTCH} 4-$ EFNB2. Results demonstrated that NOTCH4 expression, consistent with EFNB2 level, increased notably in preeclampsia EPCs compared with the normal group. Molecular analyses once again proved that NOTCH4 was a possible upstream pathway of EFNB2.

Previous research has demonstrated that the DLL4/ $\mathrm{NOTCH} 4$ signaling pathway may be positioned to function as an inhibitor of angiogenesis (Leong et al. 2002, Williams et al. 2006, Lobov et al. 2007, Steven Suchting 2007, li et al. 2010). These evidences were consistent with our results, which showed that the inhibition of DLL4/NOTCH4-EFNB2 promoted the functions of EPCs. All of these can be explained as that inhibited $\mathrm{NOTCH} 4$ led to repression of $\beta 1$-integrin, which stimulated VEGF-induced angiogenesis (Leong et al. 2002). Moreover, knockdown of NOTCH4 resulted in decreased DLL4/NOTCH4 signaling activation, which upregulated endothelial cell expression of Neuropilin-1 (Williams et al. 2006). Neuropilin-1 functioned as a co-receptor for the VEGF-A family, thus strengthening VEGFR2 activity and angiogenesis (Soker et al. 1998). In addition, $\mathrm{NOTCH} 4$ controlled the expression of EFNB2 in EPCs. EFNB2 suppressed angiogenesis by inhibiting VEGF-induced endothelium proliferation, sprouting and migration (Kim et al. 2002), and restraining VEGF2 and VEGF3 secretion (Wang et al. 2010).

EPHRINB2 was shown to suppress the function of venous endothelial cell (Kim et al. 2002) and EPCs (Liu et al. 2015). However, other evidence has demonstrated that EFNB2 promotes the growth, survival, migration, assembly, and angiogenesis of human umbilical vein endothelial cells (Salvucci \& Tosato 2012), apparently conflicting with our observations on EPCs. These contrasting results may be due to the different styles of endothelial cells, and the complexity of 'forward' and 'reverse' signaling in EPH receptor/EPHRIN family (Zhang \& Hughes 2006). Furthermore, EPCs comprise a phenotypically heterogeneous cell population and individual sub-populations of EPCs may function differently during angiogenesis and vascular remodeling (Hur et al. 2004). Besides, EFNB2 may influence endothelium proliferation, sprouting, and migration through phosphatidylinositol-3-kinase (PI3K) and SRC and mitogen-activated protein kinase (MAPK) pathways (Maekawa et al. 2003, Steinle et al. 2003). Further research is required to discover more fundamental mechanism of DLL4/NOTCH4-EFNB2 cascade that affects the functions of EPCs.

In conclusion, we demonstrated that $\mathrm{NOTCH} 4$, not $\mathrm{NOTCH} 1$, was the specific receptor for DLL4/NOTCHEFNB2 cascade. Blockade of the DLL4/NOTCH4-EFNB2 cascade to enhance angiogenic property of EPCs might act as a therapeutic tool for improving angiogenesis in preeclampsia. 


\section{Declaration of interest}

The authors declare that there is no conflict of interest that could be perceived as prejudicing the impartiality of the research reported.

\section{Funding}

This work was supported by National Natural Science Foundation of China (No. 81170584 and 81370733 to Li Zou).

\section{References}

Artavanis-Tsakonas S, Rand MD \& Lake RJ 1999 Notch signaling: cell fate control and signal integration in development. Science 284 770-776. (doi:10.1126/science.284.5415.770)

Asahara T, Murohara T, Sullivan A, Silver M, van der Zee R, Li T, Witzenbichler B, Schatteman G \& Isner JM 1997 Isolation of putative progenitor endothelial cells for angiogenesis. Science 275 964-967. (doi:10.1126/science.275.5302.964)

Burger D \& Touyz RM 2012 Cellular biomarkers of endothelial health: microparticles, endothelial progenitor cells, and circulating endothelial cells. Journal of the American Society of Hypertension 6 85-99. (doi:10.1016/j.jash.2011.11.003)

Di Mambro A, Ferlin A, De Toni L, Selice R, Caretta N \& Foresta C 2010 Endothelial progenitor cells as a new cardiovascular risk factor in Klinefelter's syndrome. Molecular Human Reproduction 16 411-417. (doi:10.1093/molehr/gaq015)

Duarte A, Hirashima M, Benedito R, Trindade A, Diniz P, Bekman E, Costa L, Henrique D \& Rossant J 2004 Dosage-sensitive requirement for mouse DIl4 in artery development. Genes \& Developmemt 18 2474-2478. (doi:10.1101/gad.1239004)

Gale NW, Dominguez MG, Noguera I, Pan L, Hughes V, Valenzuela DM, Murphy AJ, Adams NC, Lin HC, Holash J et al. 2004 Haploinsufficiency of delta-like 4 ligand results in embryonic lethality due to major defects in arterial and vascular development. PNAS 101 15949-15954. (doi:10.1073/pnas.0407290101)

Hafner C, Schmitz G, Meyer S, Bataille F, Hau P, Langmann T, Dietmaier W, Landthaler M \& Vogt T 2004 Differential gene expression of eph receptors and ephrins in benign human tissues and cancers. Clinical Chemistry 50 490-499. (doi:10.1373/clinchem.2003.026849)

Hill JM, Zalos G, Halcox JPJ, Schenke WH, Waclawiw MA, Quyyumi AA \& Finkel T 2003 Circulating endothelial progenitor cells, vascular function, and cardiovascular risk. New England Journal of Medicine 348 593-600. (doi:10.1056/NEJMoa022287)

Huang SS \& Zheng RL 2006 Rosmarinic acid inhibits angiogenesis and its mechanism of action in vitro. Cancer Letters 239 271-280. (doi:10.1016/j.canlet.2005.08.025)

Hur J, Yang HM, Yoon CH, Lee CS, Park KW, Kim JH, Kim TY, Kim JY, Kang HJ, Chae IH et al. 2007 Identification of a novel role of T cells in postnatal vasculogenesis: characterization of endothelial progenitor cell colonies. Circulation 116 1671-1682. (doi:10.1161/ CIRCULATIONAHA.107.694778)

Hur J, Yoon C-H, Kim H-S, Choi J-H, Kang H-J, Hwang K-K, Oh B-H, Lee M-M \& Park Y-B 2004 Characterization of two types of endothelial progenitor cells and their different contributions to neovasculogenesis. Arteriosclerosis Thrombosis and Vascular Biology 24 288-293. (doi:10.1161/01.ATV.0000114236.77009.06)

Kim I, Ryu YS, Kwak HJ, Ahn SY, Oh J-L, Yancopoulos GD, Gale NW \& Koh GY 2002 EphB ligand, ephrinB2, suppresses the VEGF- and angiopoietin 1-induced Ras/mitogen. FASEB Journal 16 1126-1128. (doi:10.1096/fj.01-0805fje)

Kuijper S, Turner CJ \& Adams RH 2007 Regulation of angiogenesis by Eph-ephrin interactions. Trends in Cardiovascular Medicine $\mathbf{1 7}$ 145-151. (doi:10.1016/j.tcm.2007.03.003)

Leong KG, Hu X, Li L, Noseda M, Larrivee B, Hull C, Hood L, Wong F \& Karsan A 2002 Activated Notch4 inhibits angiogenesis: role of 1-integrin activation. Molecular and Cellular Biology 22 2830-2841. (doi:10.1128/ MCB.22.8.2830-2841.2002)
Li M, Takeshita K, Ibusuki K, Luedemann C, Wecker A, Eaton E, Thorne T, Asahara T, Liao JK \& Losordo DW 2010 Notch signaling regulates endothelial progenitor cell activity during recovery from arterial injury in hypercholesterolemic mice. Circulation 121 1104-1112. (doi:10.1161/ CIRCULATIONAHA.105.553917)

Liang C, Ren Y, Tan H, He Z, Jiang Q, Wu J, Zhen Y, Fan M \& Wu Z 2009 Rosiglitazone via upregulation of Akt/eNOS pathways attenuates dysfunction of endothelial progenitor cells, induced by advanced glycation end products. British Journal of Pharmacology 158 1865-1873. (doi:10.1111/j.1476-5381.2009.00450.x)

Lin C, Rajakumar A, Plymire DA, Verma V, Markovic N \& Hubel CA 2009 Maternal endothelial progenitor colony-forming units with macrophage characteristics are reduced in preeclampsia. American Journal of Hypertension 22 1014-1019. (doi:10.1038/ajh.2009.101)

Liu X, Luo Q, Zheng Y, Liu X, Hu Y, Wang F \& Zou L 2015 The role of Delta-like 4 ligand/Notch-ephrin-B2 cascade in the pathogenesis of preeclampsia by regulating functions of endothelial progenitor cell. Placenta 36 1002-1010. (doi:10.1016/j.placenta.2015.07.123)

Lobov IB, Renard RA, Papadopoulos N, Gale NW, Thurston G, Yancopoulos GD \& Wiegand SJ 2007 Delta-like ligand 4 (DII4) is induced by VEGF as a negative regulator of angiogenic sprouting. PNAS 104 3219-3224. (doi:10.1073/pnas.0611206104)

Luppi P, Powers RW, Verma V, Edmunds L, Plymire D \& Hubel CA 2010 Maternal circulating CD34+VEGFR-2+ and CD133+VEGFR-2+ progenitor cells increase during normal pregnancy but are reduced in women with preeclampsia. Reproductive Science 17 643-652. (doi:10.1177/1933719110366164)

Maekawa H, Oike Y, Kanda S, Ito Y, Yamada Y, Kurihara H, Nagai R \& Suda T 2003 Ephrin-B2 induces migration of endothelial cells through the phosphatidylinositol-3 kinase pathway and promotes angiogenesis in adult vasculature. Arteriosclerosis Thrombosis and Vascular Biology 23 2008-2014. (doi:10.1161/01.ATV.0000096655.56262.56)

Noguera-Troise I, Daly C, Papadopoulos NJ, Coetzee S, Boland P, Gale NW, Lin HC, Yancopoulos GD \& Thurston G 2006 Blockade of Dll4 inhibits tumour growth by promoting non-productive angiogenesis. Nature 444 21-28. (doi:10.1038/nature05355)

Oh I-Y, Yoon C-H, Hur J, Kim J-H, Kim T-Y, Lee C-S, Park K-W, Chae I-H, Oh B-H, Park Y-B et al. 2007 Involvement of E-selectin in recruitment of endothelial progenitor cells and angiogenesis in ischemic muscle. Blood 110 3891-3899. (doi:10.1182/blood-2006-10-048991)

Ridgway J, Zhang G, Wu Y, Stawicki S, Liang W-C, ChantherY Y, Kowalski J, Watts RJ, Callahan C, IanKasman et al. 2006 Inhibition of Dll4 signalling inhibits tumour growth by deregulating angiogenesis. Nature 444 21-28. (doi:10.1038/nature05313)

Robb AO, Mills NL, Newby DE \& Denison FC 2007 Endothelial progenitor cells in pregnancy. Reproduction 133 1-9. (doi:10.1530/REP-06-0219)

Salvucci O \& Tosato G 2012 Essential roles of EphB receptors and EphrinB ligands in endothelial cell function and angiogenesis. Cancer Research 114 21-57. (doi:10.1016/B978-0-12-386503-8.00002-8)

Shawber CJ, Das I, Francisco E \& Kitajewski J 2003 Notch signaling in primary endothelial cells. Annals of the New York Academy of Sciences 995 162-170. (doi:10.1111/nyas.2003.995.issue-1)

Shutter JR, Scully S, Fan W, Richards WG, Kitajewski J, Deblandre GA, Kintner CR \& Stark KL 2000 Dll4, a novel Notch ligand expressed in arterial endothelium. Genes \& Development 14 1313-1318. (doi:10.1101/gad.14.11.1313)

Sipos PI, Crocker IP, Hubel CA \& Baker PN 2010 Endothelial progenitor cells: their potential in the placental vasculature and related complications. Placenta 31 1-10. (doi:10.1016/j.placenta.2009.10.006)

Soker S, Takashima S, Miao HQ, Neufeld G \& Klagsbrun M 1998 Neuropilin-1 is expressed by endothelial and tumor cells as an isoform-specific receptor for vascular endothelial growth factor. Cell 92 735-745. (doi:10.1016/S0092-8674(00)81402-6)

Steinle J, Meininger CJ, Chowdhury U, Wu G \& Granger HJ 2003 Role of ephrin B2 in human retinal endothelial cell proliferation and migration. Cellular Signalling 15 1011-1017. (doi:10.1016/S08986568(03)00072-X)

Suchting S, Freitas C, le Noble F, Benedito R, Breant C, Duarte A \& Eichmann A 2007 The Notch ligand Delta-like 4 negatively regulates endothelial tip cell formation and vessel branching. PNAS 104 3225-3230. (doi:10.1073/pnas.0611177104) 
Sugawara J, Mitsui-Saito M, Hoshiai T, Hayashi C, Kimura Y \& Okamura K 2005 Circulating endothelial progenitor cells during human pregnancy. Journal of Clinical Endocrinology and Metabolism 90 1845-1848. (doi:10.1210/jc.2004-0541)

Szpera-Gozdziewicz A \& Breborowicz G 2014 Endothelial dysfunction in the pathogenesis of pre-eclampsia. Frontiers in Bioscience 19 734-746. (doi:10.2741/4240)

The American College of Obstetricians and Gynecologists 2013 Hypertension in pregnancy. Obstetrics and Gynecology 122 11221131. (doi:10.1097/01.AOG.0000437382.03963.88)

Wang HU, Chen Z-F \& Anderson DJ 1998 Molecular distinction and angiogenic interaction between embryonic arteries and veins revealed by ephrin-B2 and its receptor Eph-B4. Cell 93 741-753. (doi:10.1016/ S0092-8674(00)81436-1)

Wang Y, Nakayama M, Pitulescu ME, Schmidt TS, Bochenek ML, Sakakibara A, Adams S, Davy A, Deutsch U, Luthi U et al. 2010 Ephrin-B2 controls VEGF-induced angiogenesis and lymphangiogenesis. Nature 465 483-486. (doi:10.1038/nature09002)

Weinmaster G 1997 The ins and outs of notch signaling. Molecular and Cellular Neuroscience 9 91-102. (doi:10.1006/mcne.1997.0612)
Williams CK, Li JL, Murga M, Harris AL \& Tosato G 2006 Up-regulation of the Notch ligand Delta-like 4 inhibits VEGF-induced endothelial cell function. Blood 107 931-939. (doi:10.1182/blood-2005-03-1000)

Yan T, Liu Y, Cui K, Hu B, Wang F \& Zou L 2013 MicroRNA-126 regulates EPCs function: implications for a role of miR-126 in preeclampsia. Journal of Cellular Biochemistry 114 2148-2159. (doi:10.1002/ jcb.24563)

Ye L \& Poh KK 2015 Enhancing endothelial progenitor cell for clinical use. World Journal of Stem Cells 7 894-898. (doi:10.4252/wjsc.v7.i6.894)

Zhang J \& Hughes S 2006 Role of the ephrin and Eph receptor tyrosine kinase families in angiogenesis and development of the cardiovascular system. Journal of Pathology 208 453-461. (doi:10.1002/(ISSN)10969896)

Received 12 March 2016

First decision 5 April 2016

Revised manuscript received 6 April 2016

Accepted 8 April 2016 